\title{
Water Requirements of Avocado in Israel. I Tree and Soil Parameters $\S$
}

\author{
D. Kalmar ${ }^{\mathrm{A}}$ and E. Lahav ${ }^{\mathrm{B}}$ \\ ${ }^{\text {A }}$ Division of Environmental Physiology and Irrigation, Agricultural Research Organization, \\ Volcani Center, Bet Dagan, Israel. \\ ${ }^{B}$ Division of Subtropical Horticulture, Agricultural Research Organization, \\ Volcani Center. \\ $\S$ Contribution No. 116-E, 1976 Series, Agric. Res. Organ., Volcani Center.
}

\begin{abstract}
The effect of different irrigation intervals on the avocado tree was tested during the years 1968-1974 in the northern coastal plain of Israel. The objectives of this experiment were: (a) to make measurements of soil and plant parameters to help understand mechanisms of response to irrigation; and (b) to establish the most suitable irrigation schedule for highest yields of export quality fruit.

The trial consisted of four irrigation treatments, at intervals of 7, 14,21 and 28 days; the respective average annual water applications were $8890,7450,6680$, and $5940 \mathrm{~m}^{3} /$ ha. The cultivars Ettinger, Fuerte and Hass were tested in five replications in randomized blocks. Soil moisture consumption was estimated by using a neutron probe and tensiometers.

Most of the water consumption was from the upper 60-cm soil layer. With the 7-day interval, the calculated daily loss from the soil profile was greater throughout the whole irrigation season than with the other intervals.

The least salt accumulation occurred under the long interval treatments since the large amounts of water supplied at each irrigation leached the salts continuously.

Reduced intervals between irrigations resulted in increased trunk growth and increased tree size. It is concluded that with a 21-day interval the vegetative growth of producing trees was restricted and therefore relatively smaller trees with easier fruit picking and delayed orchard thinning were obtained.
\end{abstract}

\section{Introduction}

Most avocado plantations in the northern coastal plain of Israel are planted jointly with, or are incorporated into, existing banana plantations. For the first few years the avocado trees are irrigated according to the requirements of the banana plants. After the removal of the bananas, irrigation schedules are changed to those which are optimal for avocados.

Very little research has been carried out in Israel or elsewhere on the water requirements of avocado trees, and the little done was mostly on the effect of intervals between irrigations, as determined with the aid of tensiometers (Richards 1950; Richards et al. 1962). In a single irrigation experiment with cv. Hass in California, 31-46 irrigations per season resulted in increases in yields and fruit size as compared with 17-26 or 8-11 irrigations per season (Richards et al. 1958, 1962). The present paper reports on the first comprehensive irrigation trial, carried out with the aims of (a) measuring soil and plant parameters to help understand mechanisms of response to irrigation, and (b) determining the best irrigation schedule for achieving highest yields of export quality fruits (Lahav and Kalmar 1977). 


\section{Methods}

In 1963 an avocado orchard was planted together with bananas at the Akko Experiment Station in the northern coastal plain of Israel. The plantation was situated on a slope of 4\%. In the summer of 1966 the banana trees were removed and soon afterwards ridges were made for surface drainage during the rainy season.

The trial was initiated in 1968 and terminated in 1974. The average rainfall and evaporation for this period are summarized in Fig. 1. Sprinklers were placed equidistant between four avocado trees planted 6 by $6 \mathrm{~m}$ apart. Water quality was very good (50 ppm chloride) and constant throughout the irrigation season. The soil was a grumusol with above $60 \%$ clay in all layers down to $150 \mathrm{~cm}$.

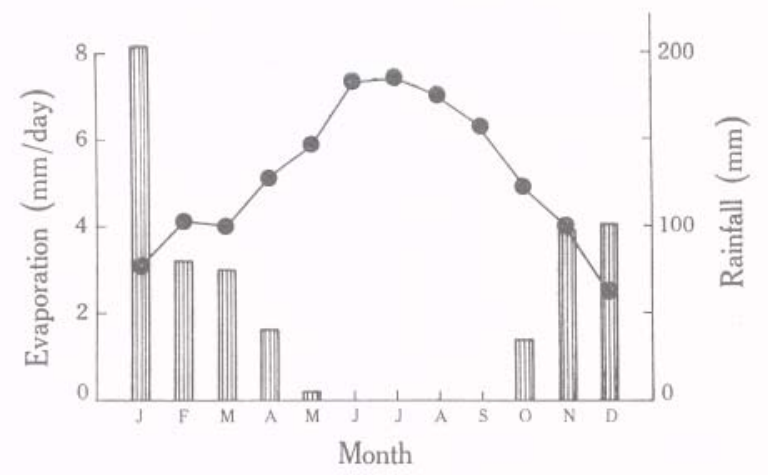

Fig. 1. Six years' average rainfall and class A pan evaporation (Akko Exp. Stn., 1968-1973).

The Ettinger, Fuerte and Hass cultivars were tested in five replications in randomized blocks. Each plot comprised nine trees and double guard rows (900 $\left.\mathrm{m}^{2}\right)$.

The trial consisted of four irrigation treatments, at intervals of 7, 14, 21 and 28 days. The respective average annual amounts of water applied were 8890, 7450, 6680 , and $5940 \mathrm{~m}^{3} / \mathrm{ha}$. In the first two treatments (7- and 14-day intervals) water was given to wet the soil to a depth of $30 \mathrm{~cm}$; additional quantities were given to wet the soil down to $90 \mathrm{~cm}$ whenever this was found necessary according to soil moisture tests. For irrigation treatments at longer intervals, water quantities were fixed according to the requirements of the $0-60 \mathrm{~cm}$ soil layer; additional amounts were given whenever needed to keep the soil moist to a depth of $120 \mathrm{~cm}$. In all treatments no excess water was given to the trees and therefore no underground drainage occurred.

The differential irrigation treatments were started in early June after the fruit had set, to avoid excessive fruit drop. Irrigation treatments were applied until the end of October.

\section{Soil and Water Tests}

Moisture tests were carried out with a neutron probe before and after each irrigation. For each treatment measurements were made in one plot with 36 access tubes, one for each sq metre between four trees. In the other four replications, four access tubes were placed according to measurements of water distribution by the sprinklers (Christiansen 1942). The neutron probe was calibrated separately to 
0-30 $\mathrm{cm}$ and $30-180 \mathrm{~cm}$ soil layers by means of parallel gravimetric measurements (Cohen 1964).

Six tensiometers were placed in a single plot of each treatment with the object of studying their use to determine irrigation needs. The depths of tensiometer placements were $30,45,90$ and $120 \mathrm{~cm}$ in 7, 14, 21 and 28-day irrigation intervals respectively.

\section{Soil Salinity}

The soil was analysed before the start of the experiment and then again every spring and autumn. Each plot was sampled and analysed separately. Soil layers (of $30 \mathrm{~cm}$ each) were sampled to a depth of $150 \mathrm{~cm}$. Estimations of $\mathrm{pH}$, exchangeable cations, sodium, chloride, potassium, and calcium + magnesium were made in the soil water extract. The sodium adsorption ratio was also calculated.

\section{Tree Size}

Measurements were made each spring and autumn. The tree radius-from the trunk to the edge, of the canopy - and the tree height were recorded. The tree volume was calculated according to Turrell (1946). The formulae used were: for cvv. Fuerte and Hass, $V=2 / 3 a b^{2}$, and for cv. Ettinger $V={ }^{4} / 3 a b^{2}$, where $V$ is the tree volume, $a$ the height and $b$ the radius. Regression analysis for tree volume on the amount of water applied was made, and the deviation from linearity calculated.

The trunk circumference was measured $20 \mathrm{~cm}$ above the graft union. Trunk growth in winter and summer was calculated.

Daily trunk expansion and contraction were registered continuously with dendrographs sensitive to changes of $10 \mu \mathrm{m}$. As the preliminary tests did not produce differences among cultivars but significant differences according to alternate bearing (Lahav et al. 1973-74, 1975), Hass trees only, in their 'on-year', were measured. Trees irrigated at 7-day intervals were compared with those irrigated every 28 days. During the 6 years of experimentation many trunks were measured. The results presented here can be regarded as typical, as the findings recorded were observed repeatedly in other trees and seasons.

\section{Results}

\section{Soil parameters}

Water extraction from the different layers is shown in Fig. 2. More water was consumed in 1972 than in 1968 because of tree growth, but the relative differences between treatments were unchanged.

The daily loss from the soil profile was affected by meteorological conditions and irrigation treatments. As temperature and evaporation increased and irrigation intervals decreased, the daily loss from the profile increased.

The relationship between the water deficit and the evaporation from a class A pan $\left(E_{t} / E_{o}\right)$ varied with the season, with a peak in August-September (Fig. 3). The irrigation interval was found to be negatively correlated with $E_{t} / E_{o}$, being high in the 7- and 14-day interval treatments compared with the other two treatments.

Most of the changes in relative water consumption occurred to a depth of $60 \mathrm{~cm}$. Water extraction in 1972 was from deeper soil layers than in 1968. The contribution of the upper layers to the total water consumption decreased with increased irrigation 
Fig. 2. Effect of irrigation interval on relative water consumption from the soil in two years.

Fig. 3. Effect of irrigation interval on the daily water deficit $\left(E_{t}\right)$ and the relationship between the water deficit and the evaporation from a class A pan $\left(E_{t} / E_{o}\right)$. Irrigation intervals: $\circ 7$ days; $\square 14$ days; $\Delta 21$ days; $\boldsymbol{\Delta} 28$ days.

Fig. 4. Effect of a 21-day irrigation interval on soil moisture tension at the $90-\mathrm{cm}$ depth throughout the irrigation season.
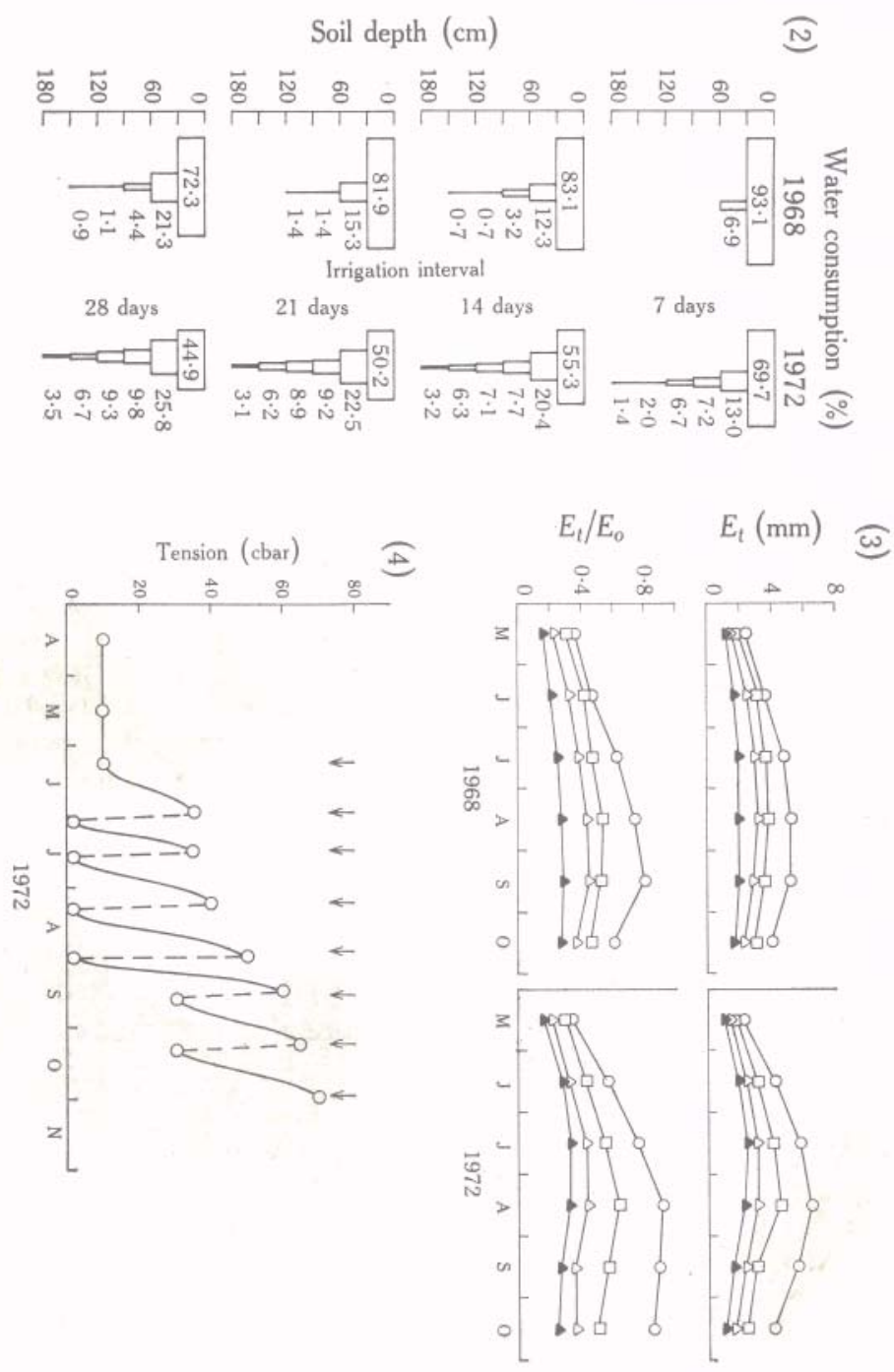
intervals. Average seasonal irrigation efficiency (the ratio between the additional moisture in the soil and the amount of water supplied) was $94-96 \%$, without differences among treatments.

The tensiometers showed the following effects of irrigation intervals on soil water tension:

7-day - the tensiometers never showed the maximal water tension (70 centibars) even when placed only $30 \mathrm{~cm}$ deep.

14-day-tensiometers located to a depth of $45 \mathrm{~cm}$ showed maximal tension after 12-14 days.

21-day-tensiometers $90 \mathrm{~cm}$ deep showed increasing tension before each irrigation, and during the irrigation season (Fig. 4).

28-day-deeper-located tensiometers $(120 \mathrm{~cm})$ did not respond to irrigation, but a continuous increase in tension was registered during the irrigation season.
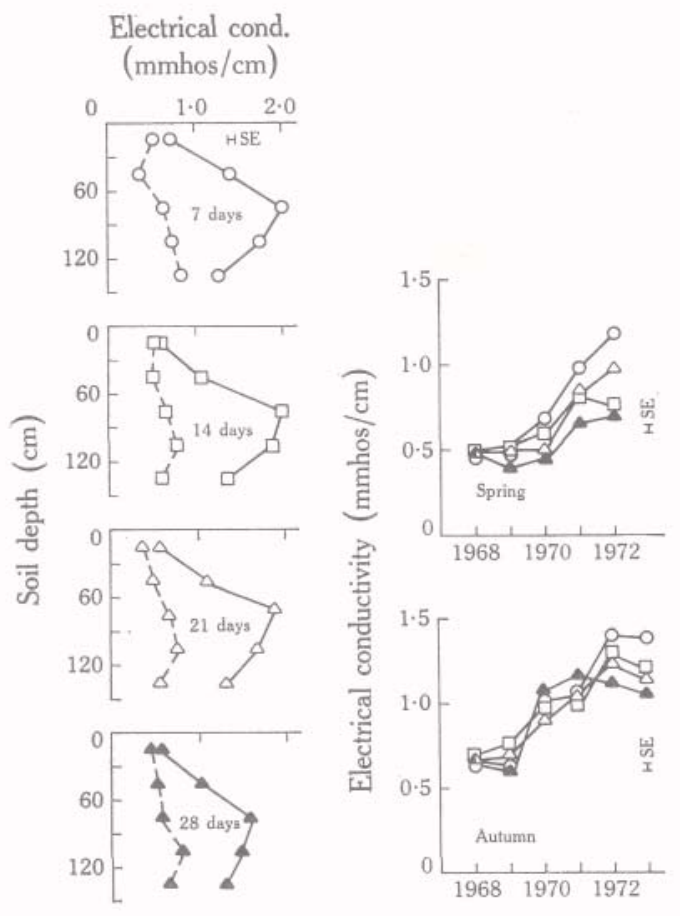

Fig. 5. Effect of irrigation interval on salt accumulation in the soil profile $(0-150 \mathrm{~cm})$ from spring 1968 (dashed lines) until autumn 1974 (solid lines, left-hand side) and during the six experimental years $(0-90 \mathrm{~cm}$, righthand side). Symbols for irrigation intervals as in Fig. 3.

The effect of irrigation interval and water quantity on soil salinity is shown in Fig. 5. During the 6 years of experimentation, pronounced salt accumulation occurred in all soil layers and in all treatments, up to $2-0 \mathrm{mmhos} / \mathrm{cm}$ (mostly below $90 \mathrm{~cm}$ ). The treatment effect was found from the third year onward. In the upper layers, salt accumulation was higher with the 7-day interval than with the other treatments, while with the 28-day interval it was lowest. Generally, as irrigation intervals shortened and the amount of water per year consequently increased (though in each irrigation it decreased), more salts accumulated in the soil profile. 


\section{Tree parameters}

\section{Tree Size}

The dimensions of trees irrigated at 7-day intervals were largest, and those of trees irrigated at 28-day intervals were smallest (Table 1).

\section{Trunk Circumference}

As the trees became older and thicker, the annual trunk growth decreased. Among the three cultivars, the increase in circumference of cv. Ettinger was highest, while that of Fuerte was smallest (Fig. 6). As irrigation intervals were shortened, the rate of increase in circumference rose.

Table 1. Effect of irrigation interval on avocado tree volume

Each figure is a mean for five plots

\begin{tabular}{|c|c|c|c|c|c|}
\hline \multirow{2}{*}{ Cultivar } & \multirow{2}{*}{$\begin{array}{c}\text { Irrigation } \\
\text { interval } \\
\text { (days) }\end{array}$} & \multicolumn{3}{|c|}{ Tree volume $\left(\mathrm{m}^{3}\right)$} & \multirow{2}{*}{$\begin{array}{c}\text { Volume } \\
\text { increase } \\
(\%)\end{array}$} \\
\hline & & 1969 & 1974 & Difference & \\
\hline \multirow[t]{5}{*}{ Ettinger } & 7 & $37 \cdot 0$ & $88 \cdot 9$ & $51 \cdot 9$ & $140 \cdot 2$ \\
\hline & 14 & $35 \cdot 0$ & $87 \cdot 4$ & $52 \cdot 4$ & $149 \cdot 7$ \\
\hline & 21 & $34 \cdot 4$ & $70 \cdot 8$ & $36 \cdot 4$ & $105 \cdot 0$ \\
\hline & 28 & $32 \cdot 2$ & $64 \cdot 5$ & $32 \cdot 3$ & $100 \cdot 0$ \\
\hline & Average & $34 \cdot 7$ & $77 \cdot 9$ & $43 \cdot 3$ & $124 \cdot 8$ \\
\hline \multirow[t]{5}{*}{ Fuerte } & 7 & $21 \cdot 1$ & $43 \cdot 5$ & $22 \cdot 4$ & $106 \cdot 2$ \\
\hline & 14 & $18 \cdot 7$ & $35 \cdot 7$ & $17 \cdot 0$ & $90 \cdot 9$ \\
\hline & 21 & $19 \cdot 7$ & $35 \cdot 0$ & $15 \cdot 3$ & $77 \cdot 7$ \\
\hline & 28 & $19 \cdot 0$ & $33 \cdot 2$ & $14 \cdot 2$ & $74 \cdot 7$ \\
\hline & Average & $19 \cdot 6$ & $36 \cdot 9$ & $17 \cdot 2$ & $87 \cdot 8$ \\
\hline \multirow[t]{5}{*}{ Hass } & 7 & $21 \cdot 5$ & $45 \cdot 3$ & $23 \cdot 8$ & $110 \cdot 7$ \\
\hline & 14 & $18 \cdot 0$ & $39 \cdot 9$ & $21 \cdot 9$ & $121 \cdot 7$ \\
\hline & 21 & $22 \cdot 0$ & $42 \cdot 1$ & $20 \cdot 1$ & $91 \cdot 4$ \\
\hline & 28 & $17 \cdot 5$ & $34 \cdot 6$ & $17 \cdot 1$ & $97 \cdot 7$ \\
\hline & Average & $19 \cdot 8$ & $40 \cdot 5$ & $20 \cdot 7$ & $104 \cdot 5$ \\
\hline \multicolumn{2}{|c|}{ Standard error of means } & $1 \cdot 5$ & $1 \cdot 9$ & $2 \cdot 2$ & \\
\hline \multirow{2}{*}{\multicolumn{2}{|c|}{$\begin{array}{l}\text { Significance of linear component } \\
\text { Deviation from linearity }\end{array}$}} & NS & 0.01 & 0.05 & \\
\hline & & Ns & NS & NS & \\
\hline
\end{tabular}

Differences were found between the effect of treatments on the winter increase in circumference compared with that of summer. Increase in trunk circumference in the summer was more rapid at shorter irrigation intervals, as mentioned above. In the winter the tendency was reversed, i.e. the 'dry' treatments showed higher growth rates. However, since summer growth was four times that of winter, the overall effect was not much changed.

Daily expansion and contraction of radius as measured by dendrometers showed remarkable differences between trees irrigated at 7-day and 28-day intervals (Fig. 7). The trunk contraction in particular was affected, being twice as high in trees irrigated at long intervals. Irrigation reduced trunk contraction in trees irrigated at long 
intervals for 9-15 days, but for 3-4 days only in trees irrigated every week. In the 'dry' treatment, trunk contraction disappeared almost completely for the first day after irrigation. Yet the total increase in radius achieved in one 28-day cycle, as compared with four intervals of 7 days each, did not differ greatly.
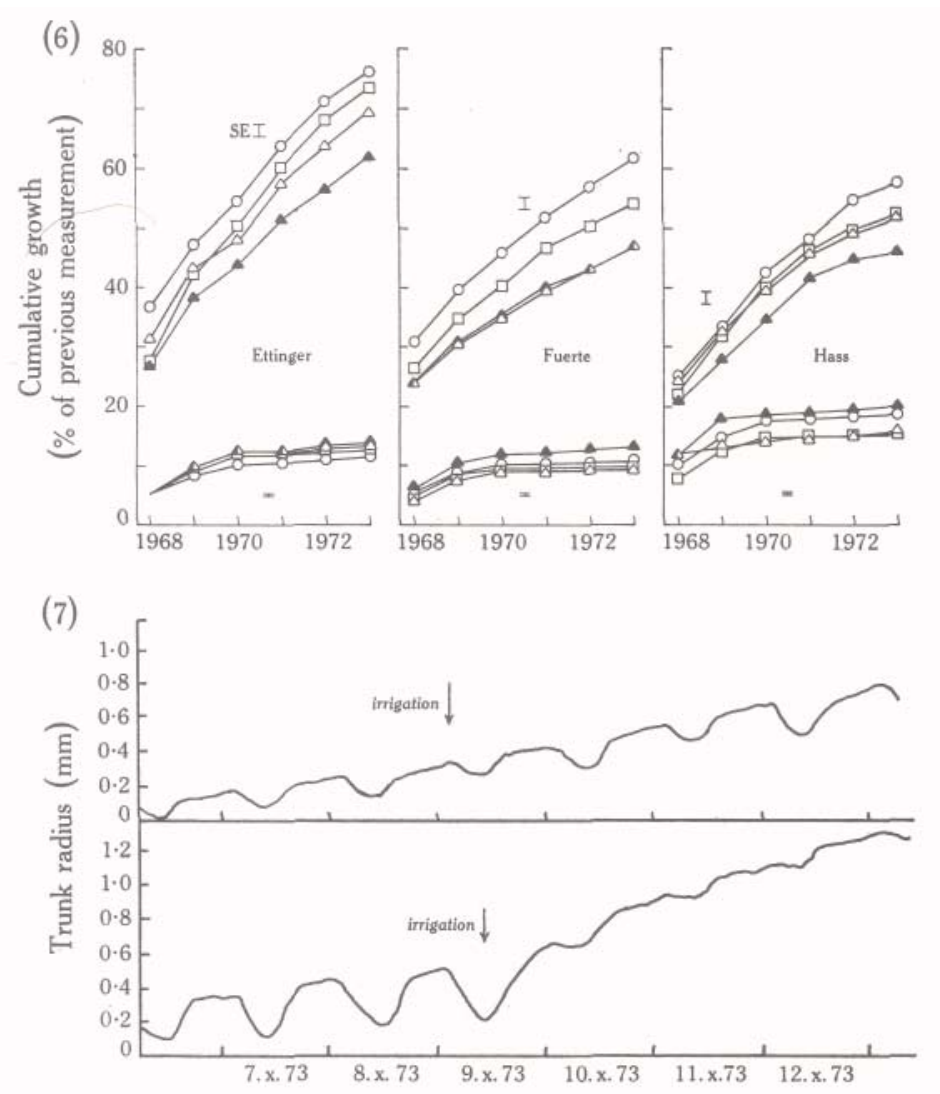

Fig. 6. Effect of irrigation interval on the summer (upper curves) and winter (lower curves) growth of the trunk circumference.

Fig. 7. Differences in effect of irrigation on changes in the trunk radius between trees irrigated at 7-day intervals (top) and those irrigated at 28-day intervals (bottom).

\section{Discussion}

On the basis of yield records presented in paper II (Lahav and Kalmar 1977), it was shown that the best treatment was that of the 21-day interval. In this treatment $600 \mathrm{~m}^{3}$ water/ha was supplied at each irrigation during June and July. Since water losses increased later in the season, irrigation rates were then increased up to 800 $\mathrm{m}^{3} / \mathrm{ha}$. It should be pointed out that in this treatment the average daily amount of water applied was only $32 \mathrm{~m}^{3} / \mathrm{ha}\left(E_{t} / E_{o}=0.50\right)$, and the seasonal amount was 6680 $\mathrm{m}^{3} / \mathrm{ha}$. These values are only $75 \%$ of the corresponding 7 -day interval values, which are normal for avocado plantations in Israel. The neutron probe measurements enabled water consumption in the whole tree area to be calculated down to a considerable depth. At the 7-day interval, the daily loss from the soil profile was higher 
during the whole irrigation season than at other intervals (Fig. 3). This can be explained by the larger tree volume caused by frequent irrigations and the higher annual total amount of water applied.

It seems that with a 21-day interval a better wetting and drying regime is obtained. It has been established that an irrigation schedule which permits considerable drying of the heavy soil results in a better soil structure, in contrast to the destruction caused by frequent irrigations, which is in fact an irrigation regime without a drying period.*

On the basis of the present findings, the relation between water deficit and the class A evaporation $\left(E_{t} / E_{o}\right)$ in avocado plantations in heavy soil can be reduced from 0-6 to 0-43 in June-August.

Under prevailing experimental conditions, tensiometers recorded the soil water tension for the 7- and 14-day irrigation intervals. It would appear that the range of tensiometers is not large enough to cover the changes in tension down to $60 \mathrm{~cm}$ in the longer irrigation intervals.

It is well known that under uniform soil and water conditions, the irrigation rate is the main factor affecting salt accumulation. In the present experiment the chloride content in the irrigation water was less than $50 \mathrm{mg} / 1$, which is far below the concentration found to be damaging to avocado trees even when grafted on Mexican rootstocks (Kadman 1963). However, the annual amount of chlorides introduced with the irrigation water $(400-600 \mathrm{~kg} / \mathrm{ha})$ was not negligible. Heavy winter rainfall during 1968-1971 leached out all the salts which had accumulated since the commencement of the experiment. Later, with reduced precipitation, a gradual increase in soil salinity was registered.

With the 7-day interval treatment, large amounts of water were supplied (6-year av., $8890 \mathrm{~m}^{3} / \mathrm{ha}$ ). In consequence, this treatment caused larger amounts of salt to be introduced into the soil. This treatment, of light but frequent irrigations, reduced the leaching process, which led to an additional relative increase in salinity in the upper soil layer. Increased water consumption by the larger trees under this treatment may add to the already low leaching capacity of this irrigation regime. In an irrigation experiment conducted with Hass trees in California, frequent irrigations also resulted in increased chloride concentrations (Bingham and Richards 1958).

The lowest salt accumulations occurred with applications at 28-day intervals, since the large amounts of water (up to $1000 \mathrm{~m}^{3} /$ ha per irrigation) leached the salts continuously. These findings should be of considerable importance in areas where avocado is grown under conditions of water shortage and high water salinity.

The average increase in tree volume during the 1968-1974 period was over $30 \mathrm{~m}^{3}$ for trees irrigated at 7- and 14-day intervals, and $22 \mathrm{~m}^{3}$ for trees irrigated at greater intervals. The response to the irrigation regime was highest with cv. Ettinger and lowest with cv. Fuerte (Fig. 8). Restricted growth as a result of a reduced water supply was also observed with Hass trees in California (Richards et al. 1962).

The trees were relatively young and not yet producing when the experiment was initiated (fifth year). Naturally, the effect of water stress on tree volume was more pronounced at this stage of growth. The main effect was on the number of flushes per season. There were three or four flushes on the trees irrigated at 7-day and 14-day intervals compared with only one or two flushes with the other two treatments.

* Kalmar, D., Dynamics of grumusol structure. Ph.D Thesis, Hebrew Univ. Jerusalem (in Hebrew, in preparation). 
The water effect on summer growth was reversed in autumn with the onset of the rains, but temperatures were still high. The autumn-accelerated growth of trees irrigated at 21-day and 28-day intervals was best observed in trunk circumference measurements, and in the daily trunk growth and contraction curves (Lahav et al. 1975).

Irrigation always caused an increase in circumference. The annual average difference in trunk radius between trees irrigated at 7-day and 28-day intervals was 1.4 $\mathrm{mm}(=1.7 \%$ of trunk radius). A qualitative difference in trunk growth was observed 18 days after irrigation (28-day interval). This corresponds with the cessation of fruit growth (Lahav et al. 1975).

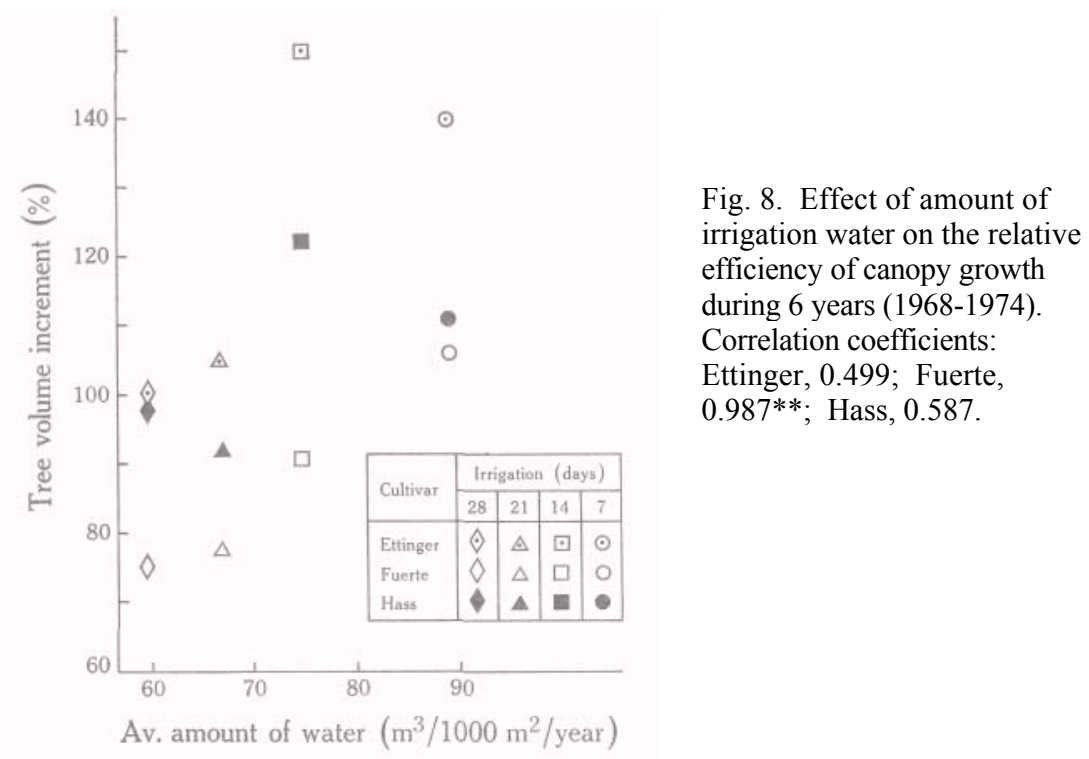

In conclusion, it can be stated that a well-planned irrigation program can be used to control avocado tree size. The growth of young trees can be accelerated and bearing thereby advanced, or the balance between the reproductive and vegetative phases may be changed by growth restriction. To ease fruit picking and delay orchard thinning, relatively small trees were obtained by irrigating every 21 days, with a total of $6680 \mathrm{~m}^{3} /$ ha water per year. This treatment did not result in lower yields, and compared favourably with the other treatments tested (Lahav and Kalmar 1977).

\section{References}

Bingham, F. T., and Richards, S. J. (1958). Effects of irrigation treatments and rates of nitrogen fertilization on young Hass avocado trees. III. Changes in soil chemical properties. Proc. Am. Soc. Hortic. Sci. 71, 304-9.

Christiansen, J. E. (1942). Irrigation by sprinkling. Bull. Calif. Agric. Exp. Stn. No. 670.

Cohen, O. P. (1964). A procedure for calibrating neutron moisture probes in the field. Israel J. Agric. Res. 14, 169-78.

Kadman, A. (1963). The uptake and accumulation of chloride in avocado leaves and the tolerance of avocado seedlings under saline conditions. Proc. Am. Soc. Hortic. Sci. 83, 280-6.

Lahav, E., and Kalmar, D. (1977). Water requirements of avocado in Israel. II. Influence on yield, fruit growth and oil content. Aust. J. Agric. Res. 28, 869-77.

Lahav, E., Kalmar, D., and Zamet, D. (1973-74). The value of physiological indicators in determining the irrigation requirements of the avocado tree. Yearb. Calif. Avocado Soc. 56, 137-46. 
Lahav, E., Kalmar, D., and Zamet, D. (1975). Daily fluctuations in the growth of avocado trunks and fruits and the effects of irrigation and meteorological conditions on them. Pamph. Agric. Res. Organ., Volcani Center, No. 149. (Hebrew, with English summary).

Richards, S. J. (1950). Soil moisture conditions in avocado groves. Yearb. Calif. Avocado Soc. $35,70-2$.

Richards, S. J., Moore, P. W., Bingham, F. T., Embleton, T. W., and Labanauskas, C. K. (1958). Avocado irrigation and nitrogen fertilization plots at the Citrus Experiment Station. Yearb. Calif. Avocado Soc. 42, 25-9.

Richards, S. J., Warneke, J. E., and Bingham, F. T. (1962). Avocado tree growth response to irrigation. Yearb. Calif. Avocado Soc. 46, 83-7.

Turrell, F. M. (1946). 'Tables of Surfaces and of Prolate and Oblate Spheroids and Spheroidal Coefficients.' (Univ. of California Press: Berkeley.)

Manuscript received 21 January 1977 